\title{
Influence of the copper content on the optical properties of CZTSe thin films
}

M.V. Yakushev, ${ }^{1,2,3}$ M.A. Sulimov, ${ }^{2}$ J. Márquez-Prieto, ${ }^{4}$ I. Forbes, ${ }^{4}$ J. Krustok, ${ }^{5}$ P.R. Edwards, ${ }^{1}$ V.D. Zhivulko, ${ }^{6}$ O.M. Borodavchenko, ${ }^{6}$ A.V. Mudryi, ${ }^{6}$ and R.W. Martin ${ }^{1}$

${ }^{1}$ Department of Physics, SUPA, University of Strathclyde, Glasgow G4 ONG, UK

${ }^{2}$ Ural Federal University, Ekaterinburg, 620002, Russia

${ }^{3}$ Institute of Solid State Chemistry of the Urals branch of the Russian Academy of Sciences, Ekaterinburg 620990, Russia

${ }^{4} N P A G$, Department of Physics and Electrical Engineering, Northumbria University, Newcastle upon Tyne NE1 8ST, UK

${ }^{5}$ Tallinn University of Technology, Ehitajate tee 5, Tallinn 19086, Estonia

${ }^{6}$ Scientific-Practical Material Research Centre of the National Academy of Sciences of Belarus, P. Brovki 19, Minsk 220072, Belarus

\begin{abstract}
We present an optical spectroscopy study of $\mathrm{Cu}_{2} \mathrm{ZnSnSe}_{4}$ (CZTSe) thin films deposited on $\mathrm{Mo} /$ glass substrates. The $[\mathrm{Cu}] /[\mathrm{Zn}+\mathrm{Sn}]$ ratio in these films varies from nearly stoichiometric to strongly $\mathrm{Cu}$ deficient and $\mathrm{Zn}$ rich. Increasing $\mathrm{Cu}$ deficiency and $\mathrm{Zn}$ excess widens the bandgap $E_{g}$, determined using photoluminescence excitation (PLE) at $4.2 \mathrm{~K}$, from $0.99 \mathrm{eV}$ to $1.03 \mathrm{eV}$ and blue shifts the dominant band in the photoluminescence (PL) spectra from 0.83 $\mathrm{eV}$ to $0.95 \mathrm{eV}$. The PL spectra of the near stoichiometric film reveal two bands: a dominant band centred at $0.83 \mathrm{eV}$ and a lower intensity one at $0.93 \mathrm{eV}$. The temperature and excitation intensity dependence of the PL spectra help to identify the recombination mechanisms of the observed emission bands as free-to-bound: recombination of free electrons with holes localised at acceptors affected by randomly distributed potential fluctuations. Both the mean
\end{abstract}


depth of such fluctuations, determined by analysing the shape of the dominant bands, and the broadening energy, estimated from the PLE spectra, become smaller with increasing $\mathrm{Cu}$ deficiency and $\mathrm{Zn}$ excess which also widens $E_{g}$ due to an improved ordering of the $\mathrm{Cu} / \mathrm{Zn}$ atoms. These changes in the elemental composition induce a significant blue shift of the PL bands exceeding the $E_{g}$ widening. This is attributed to a change of the dominant acceptor for a shallow one, and is beneficial for the solar cell performance. Film regions with a higher degree of $\mathrm{Cu} / \mathrm{Zn}$ ordering are present in the near stoichiometric film generating the second $\mathrm{PL}$ band at $0.93 \mathrm{eV}$.

Corresponding author: $\quad$ michael.yakushev@strath.ac.uk $\quad$ tel. +44141548 3374

Keywords: $\mathrm{Cu}_{2} \mathrm{ZnSnSe}_{4}$, optical spectroscopy, defects 


\section{Introduction}

$2 \mathrm{Cu}_{2} \mathrm{ZnSnSe}_{4}$ (CZTSe) is a semiconductor compound used in thin-film solar cells as the

3 absorber layer [1]. The structural and electronic properties of this material are similar to those 4 of $\mathrm{Cu}$ (InGa)Se $\mathrm{Se}_{2}$ (CIGS), successfully used in one of the leading thin film solar cell 5 technologies [2,3], while CZTSe holds the additional advantages of having elements which

6 have low costs, low toxicity and are abundant in the earth's crust. These factors provide a 7 firm foundation for the CZTSe-based photovoltaic (PV) solar cells, which currently show 8 record conversion efficiencies in excess of $11 \%$ [4] for the pure selenide version of the material. The $p$-type doping of CZTSe is assumed to be governed by its intrinsic defects $[2,5]$. Therefore understanding of the electronic properties in general and defect chemistry in particular is vital for the development of CZTSe-based solar cells. However, currently the knowledge of such properties mostly comes from theoretical studies based on density functional theory [5,6]. To become a reliable support for technology developers these theoretical findings should be verified by experimental evidence [2].

The main drawback of CZTSe-based solar cells is thought to be the small value of the open circuit voltage $\left(V_{O C}\right)[2,7]$. Its deficit for CZTSe PV measured as $E_{g} / q-V_{O C}$, where $E_{g}$ is the bandgap and $q$ the elementary charge, is significantly greater than that in good CIGSbased devices [8]. The origin of this deficit is attributed to bulk defects in the CZTSe absorber as well as to peculiarities of its lattice structure [1] which can have a degree of $\mathrm{Cu} / \mathrm{Zn}$ randomisation on the cation sub-lattice [9]. This randomisation can significantly reduce the effective bandgap, but its degree can be controlled by low temperature postgrowth annealing $[10,11]$ and the elemental composition [12]. It is important to find the particular technological parameters which can control the randomisation.

One of the most sensitive spectroscopic techniques to study the electronic properties of semiconductors in general and in particular defects with energy levels in the bandgap is 
1 photoluminescence (PL) [13]. The PL spectra of CZTSe films with small copper excess

2 reveal rather narrow peaks assigned to donor-acceptor pair (DAP) recombination mechanisms and excitonic features [14]. However in films with $\mathrm{Cu}$ deficiency and $\mathrm{Zn}$ excess (at elemental

compositions used in high performance solar cells) low temperature PL spectra reveal a single dominant band at spectral energies lower than those of DAP. Such bands are assigned to band tail related recombination mechanisms [15-18]. The band tails are considered to play an important role in the recombination processes of solar cell grade CZTSe thin films $[3,16$, $19,20]$.

According to Gokmen et al. [19] the band-tails are induced by antisite defects $\mathrm{Zn}_{\mathrm{Cu}}+\mathrm{Cu}_{\mathrm{Zn}}$ and are mainly responsible for the $V_{O C}$ deficit. However reported estimates of the mean depth of potential fluctuations in thin films of $\mathrm{Cu}_{2} \mathrm{ZnSn}(\mathrm{SSe})_{4}$ do not show much changes with varying elemental composition [20] and solar cell performances [18] suggesting that the nature of defects and their influence on solar cell performance require further investigation.

The bandgap value $E_{g}$ is essential for the development of solar cells as well as for correct interpretation of PL spectra. One of the few techniques providing $E_{g}$ for non-transparent films is photoluminescence excitation (PLE) spectroscopy. This technique can be used to determine $E_{g}$ in films deposited on Mo-coated glass and does not require a $p-n$ junction $[18,19]$.

An understanding of the electronic and optical properties is important for the sciencebased design of electronic devices but a significant practical help for technology developers can be provided by the correlation of such properties with solar cell parameters. The influence of the copper to zinc ratio $[\mathrm{Cu}] /[\mathrm{Zn}]$ on the structural properties of CZTSe and correlation of this ratio with the solar cell performance have recently been reported in [21]; however this paper did not analyse the influence of $[\mathrm{Cu}] /[\mathrm{Zn}]$ on the optical properties.

In our paper we present a detailed optical spectroscopy study of thin films of CZTSe, deposited on Mo/glass substrates, with different copper and zinc contents. We identify 
1 observed optical transitions, compare their spectral positions with the bandgaps, estimate the

2 mean depth of potential fluctuations and correlate the optical properties with the principal

3 parameters of solar cells fabricated using these films.

4

\section{2. Experimental details}

6 Metallic precursors, simultaneously deposited on Mo-coated soda-lime glass substrates by

7 magnetron sputtering of high-purity copper $(\mathrm{Cu})$, zinc $(\mathrm{Zn})$ and tin $(\mathrm{Sn})$ at room temperature, were selenised in selenium vapour/nitrogen atmosphere using a two-stage thermal annealing process $\left(5\right.$ minutes at $300{ }^{\circ} \mathrm{C}$ followed by 15 minutes at $\left.500{ }^{\circ} \mathrm{C}\right)$. Additional information on the film fabrication process can be found elsewhere [21,22,23].

The PL measurements were carried out using a $1 \mathrm{~m}$ focal length single grating monochromator and the $514 \mathrm{~nm}$ line of a $300 \mathrm{~mW} \mathrm{Ar}{ }^{+}$laser. A closed-cycle helium cryostat was employed to measure temperature dependence of the PL spectra from $6 \mathrm{~K}$ to $300 \mathrm{~K}$. An InGaAs photomultiplier tube was used to detect the PL signal in the spectral region from 0.9 $\mu \mathrm{m}$ to $1.7 \mu \mathrm{m}$.

The PLE measurements were carried out using a $0.6 \mathrm{~m}$ focal length single grating monochromator with, an InGaAs photodiode sensitive in the region from $0.9 \mu \mathrm{m}$ to $1.9 \mu \mathrm{m}$ and a liquid helium bath cryostat. A combination of a $400 \mathrm{~W}$ halogen tungsten lamp with $0.3 \mathrm{~m}$ focal length single grating monochromator was used for excitation. The PLE spectra were recorded by detecting the signal at the energy near the maximum intensity of the corresponding PL band: $0.83 \mathrm{eV}$ for film 1, $0.90 \mathrm{eV}$ for film 2 and $0.95 \mathrm{eV}$ for film 3. More experimental details can be found in ref. [14,15,18].

The elemental composition of three films grown using the same technological process from metallic precursors was examined using a combination of energy dispersive $\mathrm{x}$-ray (EDX) and X-ray fluorescence (XRF) techniques and was reported earlier [21]. The 
$1[\mathrm{Cu}] /[\mathrm{Zn}+\mathrm{Sn}]$ and $[\mathrm{Zn}] /[\mathrm{Sn}]$ ratios in the films labeled in [21] as 1,2 and 3 demonstrate a

2 gradual increase in the copper deficiency and zinc excess as shown in Table 1.

The structural properties and the presence of secondary phases, studied using room temperature Raman scattering and X-ray diffraction (XRD) as well as parameters (the open circuit voltage $V_{o c}$, short circuit current $I_{s c}$, fill factor $F$ and conversion efficiency $\eta$ ) of the solar cells fabricated of these films have been reported earlier [21]. The relevant parameters are added to Table 1.

8

\section{Results:}

\section{a. PL and PLE spectra}

The PL spectra of the three films, measured at $6 \mathrm{~K}$ and an excitation power density of 0.33 $\mathrm{W} / \mathrm{cm}^{2}$, are shown in Fig.1, with intensities normalised with respect to the dominant bands. These spectra are dominated by broad bands with maxima at $0.83 \mathrm{eV}$ (film 1), $0.90 \mathrm{eV}$ (film 2) and $0.95 \mathrm{eV}$ (film 3). The rise of the intensity from the low energy side of the bands is rather gentle in comparison with the more abrupt fall from the high energy side. The full width at half maximum (FWHM) of these bands decreases from $96 \mathrm{meV}$ for film 1 and 92 $\mathrm{meV}$ for film 2 to $90 \mathrm{meV}$ for film 3. The maximum intensity of the dominant bands in film 1 is much lower (by a factor of 400) than those in film 2 and 3 whose maximum intensities are close.

The film $1 \mathrm{PL}$ spectrum also reveals a low intensity band at $0.93 \mathrm{eV}$. Its maximum intensity is about one order of magnitude smaller than that of the dominant band whereas the FWHM of $85 \mathrm{meV}$ is slightly smaller than that of the dominant band. Oscillations associated with water vapour absorption can be seen in the spectra at $0.9 \mathrm{eV}$. 
1 Our PL measurements of CZTSe thin films deposited on bare glass substrates

2 simultaneously with those on Mo/glass in the present study demonstrate a broad dominant

3 band very similar to those in $[18,21]$.

4 The excitation intensity dependence of the PL spectra for the three films is shown in Fig.2.

5 Assuming the integrated intensity $I(P)$ under the dominant band to be dependent on the

6 excitation laser power $P$ as $I \sim P^{k}$ we determine $k$ power coefficients measuring the gradient

7 of $\log -\log$ plots of $I(P)$. Values of $k 0.79,0.94$ and 0.99 for films 1,2 and 3, respectively, are

8 shown in Table 2. Radiative recombination of charge carriers localised at defects with energy

9 levels below the bandgap is assigned for $k$ values smaller than unity. At $k$ greater than unity

10 the recombination does not involve localisation at defects [24,25]. In the chalcopyrites and

11 kesterites $k$ greater than unity can be expected for the band-to-band (BB) mechanism: recombination of free electrons from the conduction band with free holes from the valence band $[25,26]$. The BB transition was observed in the PL spectra of CZTSe from cryogenic temperatures up to $300 \mathrm{~K}[18,22]$. It was suggested that it can be present in the dominant band as a non-resolved component increasing the $k$ value. The $k$ value of the second band at $0.93 \mathrm{eV}$ in the PL spectra of film 1 is 0.93 . It is closer to $k$ for film 3 rather than to that for the dominant band of film 1 .

There is a clear tendency of an increase in $k$ as $[\mathrm{Cu}] /[\mathrm{Zn}+\mathrm{Sn}]$ becomes smaller from film 1 to 3. The determined values of $k$ suggest that the dominant PL bands are mostly associated with recombination involving defect levels within the bandgap.

The dominant bands in all three films as well as the band at $0.93 \mathrm{eV}$ for film 1 show significant shifts to higher energies with increasing laser power, whereas their shape in general and FWHM in particular do not change. The $j$ - shift, the rate of the shift per decade of the laser power change, increases from $13 \mathrm{meV}$ to $16 \mathrm{meV}$ per decade for films 1 and 2 and then falls to $12 \mathrm{meV}$ per decade for films 3 . 
$1 \quad$ Fig.3 shows the temperature dependence of the PL spectra shown on a logarithmic scale.

2 In the PL spectra of film 1, shown in Fig.3(a), the dominant band at $0.83 \mathrm{eV}$ and the second

3 band at $0.93 \mathrm{eV}$ quench by $100 \mathrm{~K}$ revealing a broad and low intensity emission band at 0.78

$4 \mathrm{eV}$. The first signs of the band appear in the $80 \mathrm{~K}$ spectrum of film 1 but the low energy cut

5 off limit of the detector might be modifying its shape. The high level of noise along with the

6 low intensity prevents reliable information to be obtained for this peak. Both dominant bands

7 in film 2 and 3 persist up to a temperature of $200 \mathrm{~K}$. At higher temperatures both spectra

8 show broad and rather low intensity bands at $0.98 \mathrm{eV}$ and $1.02 \mathrm{eV}$, respectively. Earlier [18,

$922]$ such bands have been assigned to BB recombination.

10 With rising temperature the dominant bands reveal clear red shifts in all three films. Such temperature red shifts as well as the $j$-shift values and the characteristic asymmetric shape of these bands can be taken as evidence of a band tail related mechanism underlying these emission bands [25]. In highly doped semiconductors the electron and hole densities of states below the conduction band energy $E_{c}$, and/or above the valence band energy $E_{v}$, form band tails. When the concentration of charged defects is high such tails can originate from spatial potential fluctuations [25, 26] or from spatial fluctuations of the bandgap [27]. There is no clear evidence reported so far on which of the above origins is correct for CZTSe. However the theory of spatial potential fluctuations has been well adopted for the interpretation of PL spectra. Their shape, excitation intensity and temperature dependences [25] carry a number of characteristic signs which can be found in the PL spectra observed in this study. They all suggest that the observed band tails originate from spatial potential fluctuations. Therefore we used the theory proposed in [25] to analyse the recombination mechanisms of the PL bands in this study. 
Fig.4 shows the PLE spectra, measured to determine the bandgap of the films at $4.2 \mathrm{~K}$, in comparison with PL spectra for the three films. The low energy side of the PLE spectra, representing the absorbance $\alpha(E)$ has been fitted with sigmoidal functions proposed in [28]:

$$
\alpha(h v)=\alpha_{0} /\left[1+\exp \left(E_{g}-h v\right) / \Delta E\right]
$$

where $h v$ is the photon energy, $\alpha_{0}$ vertical scale parameter and $\Delta E$ a broadening energy [29].

These fits are shown in Fig. 4 as red solid lines. The determined values of the bandgap are $(0.99 \pm 0.01) \mathrm{eV},(1.02 \pm 0.01) \mathrm{eV}$ and $(1.03 \pm 0.01) \mathrm{eV}$, for films 1,2 and 3 , respectively, are presented in Table 2. Such a considerable increase of the bandgap by $40 \mathrm{meV}$ from film 1 to film 3 is followed by a significant decrease of the broadening energy from $29 \mathrm{meV}$ to 20 meV.

\section{b. Analysis of PL spectra}

The kesterite thin films used for the absorber layer in high performance solar cells are considered to be highly doped and compensated semiconductors $[2,3,30]$. The condition for high doping (defined as the average distances between defects being smaller than their Bohr radii) may be satisfied in the kesterites for electrons but not for holes. This is because the mass of the electrons (the density of states, DOS, mass of electrons $m^{*}{ }_{e}=0.08 m_{0}$, where $m_{0}$ is the mass of free electron) is much smaller than that of the holes (the DOS mass of holes $m^{*}{ }_{h}=$ $\left.0.21 m_{0}\right)$ [31]. The proximity of defects causes an overlap of their donor wave-functions whereas their acceptors are not degenerate and holes can be considered to be classical particles [25,32]. This model is also used for the interpretation of PL spectra of the chalcopyrites $[26,33,34]$. 
1 According to [26] there are two likely transitions we can expect in the low temperature PL

2 spectra of the kesterites: (1) band-to-tail (BT) transition - the recombination of holes,

3 localised at acceptor-like states of the valence band tail, with free electrons from the

4 conduction band and (2) free-to-bound (FB) transition - the recombination of free electrons

5 with holes localised at acceptors, which are deeper than the mean energy depth of potential

6 fluctuations. The energy levels of these acceptors are affected by the valence band tails.

7 Therefore the characteristic features of the BT bands - shape, significant $j$-shift and red shift

8 with temperature rise dependence can also be found in the FB bands $[25,33,35]$.

The low-energy side of bands associated with BT recombination is determined by the density of states (DOS) of the valence band tail $\rho_{v}[25,26,36]$ which at low temperatures can be described as follows:

$$
\rho_{v}(\varepsilon) \sim \exp (-\varepsilon / \gamma)
$$

where $\gamma$ is the mean energy depth of the potential energy fluctuations of the valence band and $\varepsilon$ is the energy from the valence band top. Thus if the dominant bands is the BT recombination the low energy side can be used to estimate $\gamma[26,36]$.

An alternative interpretation of the dominant band nature could be to assign it to the FB recombination.

The FB recombination includes both the recombination of free electrons with holes captured at acceptors and holes first captured at the valence band tail and then captured at acceptors. Due to potential fluctuations the hole density of states for the FB transitions is spread at the acceptor's level:

$$
\rho_{a}(\varepsilon)=\left(N_{a} / \sqrt{2 \pi} \gamma\right) \exp \left[-\left(\varepsilon-I_{a}\right)^{2} / 2 \gamma^{2}\right],
$$

where $I_{a}$ is the acceptor ionisation energy whereas $N_{a}$ is its concentration [25, 33]. Therefore the hole density of states at the valence band tail also determines the shape of the low energy side of the FB band, and its shape can also be used to determine $\gamma$. To find out if the dominant 
1 band is the BT or FB we have to carry out temperature quenching analysis and find the

2 activation energy. If the activation energy is close to $\gamma$ then the band can be assigned to the

3 BT transition. However if the activation energy is significantly greater than $\gamma$ then the band is

4 more likely to be the FB transition.

5 For accurate analysis of the bands their shape $I(h v)$ was fitted with the empirical 6 asymmetric double sigmoidal function (DSF) proposed in [26] for bands associated with 7 band-tail recombination:

$$
\begin{aligned}
& I(h v)=A\left\{1+\exp \left[-\frac{\left(h v-E_{1}\right)}{W_{1}}\right]\right\}^{-1} * \\
& \left\{1-\left(1+\exp \left[-\frac{\left(h v-E_{2}\right)}{W_{1}}\right]\right)^{-1}\right\},
\end{aligned}
$$

where $A, E_{1}, E_{2}, W_{1}$ and $W_{2}$ are fitting parameters representing the low energy $\left(E_{1}, W_{1}\right)$ and high energy $\left(E_{2}, W_{2}\right)$ sides. Examples of fitting are shown in Fig.5. It can be seen that the best fits of DSF reasonably describe the low energy side of the dominant bands whereas the high energy side of the bands for film 2 and especially for film 3 goes slightly higher than the DSF fits. However at temperatures above $90 \mathrm{~K}$ the DSF fits to the high energy side also become very accurate. We speculate that this may be due to the presence of low intensity PL bands merging with the dominant bands and quenching at $90 \mathrm{~K}$.

We can use the fitted shapes to improve the accuracy of calculations of the temperature dependence of the band integral intensity for the two bands in film 1 by subtracting one of the bands and analysing separately the temperature and excitation intensity dependencies of the other. However the low intensity and high level of noise of the $0.93 \mathrm{eV}$ band resulted in a low accuracy of the fitting and does not allow analysis of its shape and to obtain reliable values of $W_{1}, W_{2}$ and $\gamma$. 
1 The average depth of potential fluctuations in the band tails of 39, 29 and $24 \mathrm{meV}$,

2 estimated from the low energy sides of the dominant bands in the $6 \mathrm{~K}$ PL spectra of films 1, 2

3 and 3, respectively, are shown in Table 2. The accuracy of these values is lower for the

4 dominant band of film 1 due to lower intensity of the PL emission. The presence of

5 oscillations associated with water vapour also introduces additional error in the fitting for

6 film 2. Therefore the most reliable value of $\gamma$ is found for film 2 . The decrease in the

$7 \quad[\mathrm{Cu}] /[\mathrm{Zn}+\mathrm{Sn}]$ ratio from film 1 to 3 is followed by a reduction of $\gamma$.

8

The temperature dependence of $W_{l}$ in the 3 films is shown in Fig.6(a). It can be seen that for each film $W_{l}$ does not change up to about $50 \mathrm{~K}$ and its value is close to the corresponding values of $\gamma$ for that film. Similar temperature dependencies of $W_{l}$ have been reported in [26] for the chalcopyrites.

The temperature dependence of the spectral energy of the PL intensity maxima $E_{\max }(T)$ for the observed bands is presented in Fig.6(b). It can be seen that with rising temperature all the bands shift to lower energy. The greatest shifts reveal bands in the spectra of films 2 and 3 . The film 1 bands both demonstrate red shifts confirming that they both are associated with band tails, however their shifts are significantly smaller than those of films 2 and 3.

At low temperatures the valence band-tail states act very similar to hydrogen-like acceptor states. They localise holes which can however recombine with free electrons from the degenerate donor states in the conduction band. Once the temperature rises shallow states of the band-tails release their holes whereas holes captured by deeper states stay localised resulting in a red shift of the bands which can be seen in Fig. 3 and Fig. 6(b). At low temperatures the temperature dependence of the $\mathrm{BT}$ and $\mathrm{FB}$ band maxima $E_{\max }(\mathrm{T})$ can be described as [25]:

$$
E_{\text {max }}(T)=E_{\text {max }}(6 K)-k T \ln \left[N_{v} /(p+\theta n)\right],
$$


1 Where $N_{v}$ is the valence band effective density of states, $n$ is the concentrations of free

2 electrons, $p$ is the concentrations of free holes, $\theta$ is the ratio of electron to hole probabilities

3 to be captured at the localised state. At low temperatures and low excitation intensities

4 increasing temperature induces red shifts to the band. The minimum value of $E_{\max }(\mathrm{T})$ depends

5 on the carrier concentration which in turn depends on the excitation intensity. Higher

6 excitation intensities and carrier concentrations reduce the red shift of $E_{\max }(T)$ because of

$7 \quad$ higher $n$ and $p$.

8 Arrhenius analysis of the temperature quenching of the dominant bands and the band at

$90.93 \mathrm{eV}$ in the PL spectra of film 1 was carried out using their integrated intensities.

10 Arrhenius plots of the resulting intensities for the three films are shown in Fig. 7. The best

fits have been achieved for a single recombination channel and assuming a temperature dependence of the hole capture cross section proposed in [37]:

$$
I(T)=I /\left[1+\mathrm{A}_{1} T^{3 / 2}+\mathrm{A}_{2} T^{3 / 2} \exp \left(-E_{a} / k_{B} T\right)\right]
$$

where $I$ is the integrated intensity of the analysed band at $6 \mathrm{~K}$, the lowest temperature considered temperature, $\mathrm{A}_{1}$ and $\mathrm{A}_{2}$ are process rate parameters and $E_{a}$ is activation energy. at $0.93 \mathrm{eV}$ in the PL spectra of film 1.

For the dominant bands in the PL spectra of film 2 and 3 activation energies of $98 \mathrm{meV}$ and $63 \mathrm{meV}$ were found. These activation energies along with their error corridors are shown in Table 2.

All the determined activation energies are greater than $\gamma$ indicating that all the three dominant bands as well as the band at $0.93 \mathrm{eV}$ in the PL spectra of film 1 are likely to be related to FB transitions, the recombination of free electrons with holes localised by 
1 conventional acceptors with bandgap energy level position spread by spatial potential

2 fluctuations.

\section{3. Discussion}

5 The gradual fall of the copper content from film 1 to film 3 along with a simultaneous rise in 6 that of zinc (i.e. decreasing the $[\mathrm{Cu}] /[\mathrm{Zn}+\mathrm{Sn}]$ ratio and increasing the $[\mathrm{Zn}] /[\mathrm{Sn}]$ one) suggests

7 high concentrations of the A-type defects (charge compensated defect clusters $\mathrm{V}_{\mathrm{Cu}}+\mathrm{Zn}_{\mathrm{Cu}}$ ) in 8 films 2 and 3 [38]. These changes of the elemental composition results in a dramatic 17\% 9 improvement in the solar cell efficiency defined by more than $18 \%$ rise in $V_{o c}$ whereas $J_{s c}$ in the solar cell based on film 3 shows a 5\% fall in comparison with that for the cell based on film $1[21]$.

Let us try to analyse these changes and correlate them with the optical spectroscopy parameters presented in the previous chapter.

One of the most important electronic properties of semiconductors for an absorber layer is $E_{g}$. The bandgap defines limitations for open circuit voltage. However $V_{o c}$ also depends on the absorber material transport properties such as doping level and carrier lifetime determining the open circuit voltage deficit [2]. The reduction of the $[\mathrm{Cu}] /[\mathrm{Zn}+\mathrm{Sn}]$ ratio from film 1 to 3 results in an increase of the bandgap by $40 \mathrm{meV}$ from $0.99 \mathrm{eV}$ to $1.03 \mathrm{eV}$ suggesting that the rise of $V_{o c}$ by $67 \mathrm{meV}$ [21] in the cell based on film 3 should also be attributed to improvements in the transport properties. The PLE bandgap values measured at

$6 \mathrm{~K}$ are slightly smaller than those determined at room temperature [21] from external quantum efficiency (EQE) spectra. This mismatch can be attributed to the difference in the measurement techniques. Also the technological processes, used for the fabrication of solar cell such as $\mathrm{KCN}$ etching, chemical bath deposition of $\mathrm{CdS}$ and magnetron sputtering deposition of $\mathrm{ZnO}$, can modify the material due to unintentional annealing or/and inter- 
1 diffusion between the CZTSe and CdS layers. However the room temperature EQE-measured

2 values of $E_{g}$ demonstrate the similar trend of increasing from film 1 to film 3.

The reduction of $[\mathrm{Cu}] /[\mathrm{Zn}+\mathrm{Sn}]$ is followed by blue shifts of the spectral position of the dominant band from $0.83 \mathrm{eV}$ to $0.95 \mathrm{eV}$. In the literature the spectral position of such bands in CZTSe can be found within the energy range from $0.8 \mathrm{eV}$ to $0.96 \mathrm{eV}[15-18,39]$. This scatter is assigned to the $\mathrm{Cu} / \mathrm{Zn}$ disorder degree reducing the bandgap and red shifting the dominant band in the PL spectra [11]. Paris et al. [12] show that the $\mathrm{Cu} / \mathrm{Zn}$ disorder can also be suppressed by shifting the elemental composition towards copper deficiency experimentally confirming the theoretical prediction that $\mathrm{Zn}_{\mathrm{Cu}}+\mathrm{Cu}_{\mathrm{Zn}}$ defects reduce the bandgap whereas $\mathrm{Zn}_{\mathrm{Cu}}+\mathrm{V}_{\mathrm{Cu}}$ defects increase it [40,41]. Therefore the observed increases of the bandgap can be attributed to a decrease in the population of $\mathrm{Zn}_{\mathrm{Cu}}+\mathrm{Cu}_{\mathrm{Zn}}$ and an increase in that of $V_{C u}$ and $\mathrm{Zn}_{\mathrm{Cu}}+\mathrm{V}_{\mathrm{Cu}}$ supressing the $\mathrm{Cu} / \mathrm{Zn}$ randomisation. At high $[\mathrm{Cu}] /[\mathrm{Zn}+\mathrm{Sn}]$ in film 1 the bandgap of $0.99 \mathrm{eV}$ and the spectral position of the dominant band at $0.83 \mathrm{eV}$ suggest a high level of $\mathrm{Cu} / \mathrm{Zn}$ disorder whereas at low $[\mathrm{Cu}] /[\mathrm{Zn}+\mathrm{Sn}]$ in film 3 the bandgap of $1.032 \mathrm{eV}$ and the spectral position of the dominant band at $0.95 \mathrm{eV}$ suggest a low level of disorder.

The increase in $E_{g}$ should induce a blue shift in the PL band, which is indeed observed in our PL spectra. The $120 \mathrm{meV}$ total blue shift of the dominant PL band, caused by the elemental composition changes, exceeds the $40 \mathrm{meV}$ increase of $E_{g}$. Blue shifts have been observed in the PL spectra of CZTSe films after low temperature annealing increasing the degree of $\mathrm{Cu} / \mathrm{Zn}$ ordering [11]. These shifts were found to be close to the corresponding changes in $\mathrm{E}_{\mathrm{g}}$. Although the rise in the degree of $\mathrm{Cu} / \mathrm{Zn}$ ordering does increase $V_{O C}$ it did not improve the $V_{O C}$ deficit [42]. In our study we cannot calculate the deficit of $V_{O C}$ because the solar cell parameters in Table 1 have been measured [21] at room temperature whereas our optical measurements were carried out at $6 \mathrm{~K}$. 
1 The nature of a blue shift of the dominant PL band depends on the recombination type. In

2 disordered CZTSe with the BT recombination blue shift suggests a reduction in the depth of

3 the band tails. For the FB type recombination such a shift manifests a change in the dominant

4 acceptor [25] which is not necessarily accompanied by changes in the band tail depth because

5 the tail can be induced by defects which might not include the dominant acceptors.

6 Subtracting the $40 \mathrm{meV}$ change in the bandgap we obtain a $80 \mathrm{meV}$ blue shift of the band

7 with respect to the bandgap indicating a change of the dominant acceptor for a shallower one.

8 The activation energies, shown in Table 2, reflect ionisation energies of the dominant

9 acceptors responsible for the FB transition assigned to the dominant bands. For film 1 the

10 activation energy is $E_{a}=90 \mathrm{meV}$. We can speculate that it is consistent with the acceptor

$11 \mathrm{Cu}_{\mathrm{Zn}}$ which according to [19] induces the band tails. At near-stoichiometric contents of copper and zinc this is supported by theoretical studies [5]. The same dominant acceptor with $E_{a}=90 \mathrm{meV}$ can probably be assigned to the $0.93 \mathrm{eV}$ band in the PL spectra of film 1 . The activation energy of $E_{a}=98 \mathrm{meV}$ in film 2 is quite close to that in film 1 . Therefore the dominant acceptor in film 2 probably remains the same. However the reduction in the activation energy for film 3 down to $E_{a}=63 \mathrm{meV}$ is indicative of a possible change in the nature of the acceptor. We can speculate that it is the earlier proposed antisite defect $\mathrm{Zn}_{\mathrm{Sn}}$ [18] which does not induce band tails [19]. At zinc excess and tin deficient conditions its presence is supported by theory [5].

This suggestion is also supported by the evolution of the mean energy depth of potential fluctuation (shown in Table 2) which decreases from $39 \mathrm{meV}$ in film 1 to $24 \mathrm{meV}$ in film 3. A similar reduction from film 1 to film 3 in the broadening energy $\Delta \mathrm{E}$ used to determine $\mathrm{E}_{\mathrm{g}}$ from the PLE spectra is an additional confirmation of improvements in the electronic properties of the material. 
1 The determined values of $\gamma$ are close to those estimated earlier [18, 21, 43] but smaller

2 than those for $\mathrm{Cu}_{2} \mathrm{ZnSn}(\mathrm{SSe})_{4}$ - based absorbers fabricated using a different technology [20]

3 and used to produce solar cells with conversion efficiencies up to $4.4 \%$. The mean depth of

4 the potential fluctuations $\gamma$ might not be a universal indicator of the efficiency of solar cells

5 but could be an indicator of the presence of specific defects generating such tails.

Assuming high concentrations of $\mathrm{Zn}_{\mathrm{Cu}}+\mathrm{Cu}_{\mathrm{Zn}}$ defect complexes in film 1 and their low concentrations in film 3 we see a correlation of such concentrations with $\gamma$ and $\Delta E$ suggesting that band tails might indeed be induced by the antisite defects $\mathrm{Zn}_{\mathrm{Cu}}$ and $\mathrm{Cu}_{\mathrm{Zn}}$ and their defect complex $\mathrm{Zn}_{\mathrm{Cu}}+\mathrm{Cu}_{\mathrm{Zn}}$ as proposed in [3, 19]. With increasing deviation from stoichiometry towards copper deficiency and zinc excess we should have a reduction in the $\mathrm{Cu}_{\mathrm{Zn}}$ population probably resulting in a saturation of the rise of the $\gamma$ values reported in [20].

As well as the dominant band the film 1 PL spectrum shows a low intensity band at 0.93 $\mathrm{eV}$. We speculate that film 1 might contain CZTSe volumes with different degrees of $\mathrm{Cu} / \mathrm{Zn}$ ordering resulting in different $\mathrm{E}_{\mathrm{g}}$. Comparing the PL intensity of the two bands one can see that the film is dominated by volumes with low degree of $\mathrm{Cu} / \mathrm{Zn}$ ordering generating the high intensity band at $0.83 \mathrm{eV}$. Also a small fraction of the film has higher degree of $\mathrm{Cu} / \mathrm{Zn}$ ordering generating the low intensity band at $0.93 \mathrm{eV}$. The band at $0.93 \mathrm{eV}$ shifts with a rate of $j=10 \mathrm{meV}$ per decade of excitation power which is close to the $j=11 \mathrm{meV}$ value for the dominant band of film 3 where the degree of $\mathrm{Cu} / \mathrm{Zn}$ ordering is high. Also $k=0.93$ of this band is greater than $k=0.79$ of the dominant band in the PL spectra of film 1 and corresponds more closely to that of film 3. Fig.6 shows that the red shift of both bands in the PL spectra of film 1 with increasing temperature is smaller than those of other films. Formula be due to higher concentration of charge carriers in film 1 . 
1 The $5 \%$ reduction of $J_{s c}$ in the solar cell based on film 3 in comparison with that for the

2 cell based on film 1 can be explained by a reduction of the photon flux due to the $4 \%$ increase in $E_{g}$ resulting in a $6.5 \%$ fall of the upper limit available for the short-circuit current density at air mass 1.5 illumination conditions.

5

\section{6. Conclusion}

We have presented a PL and PLE study of CZTSe absorber films, deposited on Mo-coated glass substrates and fabricated by the selenisation at $500{ }^{\circ} \mathrm{C}$ of metallic precursors. The $\mathrm{Cu}$ deficiency and $\mathrm{Zn}$ excess in these films changed from near stoichiometry to strongly $\mathrm{Cu}$ deficient and $\mathrm{Zn}$ rich.

We analyse the shape and spectral position of the PL bands, excitation intensity and temperature dependence as well as their temperature quenching activation energies $E_{a}$ and compare them with $E_{g}$ determined using PLE measurements at $4 \mathrm{~K}$.

We demonstrate that increasing copper deficiency and zinc excess blue shift the dominant band in the PL spectra from $0.83 \mathrm{eV}$ to $0.95 \mathrm{eV}$

This blue shift in the band, exceeding significantly the widening of $E_{g}$, is accompanied by a fall in the mean depth of potential fluctuations $\gamma$ (from $39 \mathrm{meV}$ to $24 \mathrm{meV}$ ) and the broadening energy in the PLE spectra (from $29 \mathrm{meV}$ to $20 \mathrm{meV}$ ). Our analysis suggests that (1) the observed PL bands are associated with the recombination of free electrons with holes localised at dominant acceptors affected by randomly distributed potential fluctuations, and that (2) changing elemental composition induces a change in the dominant acceptor type for a shallower one inducing additional reduction of $V_{O C}$.

The changes in the optical spectroscopy parameters along with improvements in the solar cell performance are consistent with a reduction of the $\mathrm{Cu}_{\mathrm{Zn}}$ defect population, and a rising concentration of $\mathrm{V}_{\mathrm{Cu}}$ and $\mathrm{Zn}_{\mathrm{Cu}}-\mathrm{V}_{\mathrm{Cu}}$ as well as with increasing ordering of $\mathrm{Cu}$ and $\mathrm{Zn}$ atoms in 
1 the (001) plane of the kesterite structure. However some volumes with higher $\mathrm{Cu} / \mathrm{Zn}$ order

2 are present in the near stoichiometry film and lead to the observed $0.93 \mathrm{eV}$ PL band.

\section{Acknowledgement}

5

6 This work was supported by the Royal Society, RFBR (14-02-00080 and 16-29-06410), 7 BRFFR (F15IC-025), UB RAS (grant 15-20-3-11), Belarus project "Nanomaterials and 8 nanotechnology" (grant No.2.56), Act 211 of the Government of Russia 02.A03.21.0006,

9 IUT 19-28 of the Estonian Ministry of Education and Research, the EU through the European 10 Regional Development Fund (project TK141), and by FP7 CHEETAH, EC grant 609788.

\section{References}

[1] X. Liu, Y. Feng, H. Cui, F. Liu, X. Hao, G. Conibeer, D.B. Mitzi, M. Green, The current status and future prospects of kesterite solar cells: a brief review, Prog. Photovolt. 24 (2016) 879-898.

[2] S. Siebentritt, S. Schorr, Kesterites - a challenging material for solar cells, Prog. 17 Photovolt. 20 (2012) 512-519.

[3] M.J. Romero, H. Du, G. Teeter, Y. Yan, M.M. Al-Jassim, Comparative study of the luminescence and intrinsic point defects in the kesterite $\mathrm{Cu}_{2} \mathrm{ZnSnS}_{4}$ and chalcopyrite $\mathrm{Cu}(\mathrm{In}, \mathrm{Ga}) \mathrm{Se}_{2}$ thin films used in photovoltaic applications, Phys. Rev. B 84 (2011) 165324-1$165324-5$

[4] Y.S. Lee, T. Gershon, O. Gunawan, T.K. Todorov, T. Gokmen, Y. Virgus, S. Guha, $\mathrm{Cu}_{2} \mathrm{ZnSnSe}_{4}$ Thin-Film Solar Cells by Thermal Co-evaporation with $11.6 \%$ Efficiency and Improved Minority Carrier Diffusion Length, Adv. Energy Mater. 5 (2015) 1401372-1$1401372-4$ 
1 [5] S. Chen, A. Walsh, X.G. Gong, S.H. Wei, Classification of lattice defects in the kesterite

$2 \mathrm{Cu}_{2} \mathrm{ZnSnS}_{4}$ and $\mathrm{Cu}_{2} \mathrm{ZnSnSe}{ }_{4}$ earth-abundant solar cell absorbers, Adv. Mater. 25 (2013)

$3 \quad 1522-1539$

4 [6] C. Persson, Electronic and optical properties of $\mathrm{Cu}_{2} \mathrm{ZnSnS}_{4}$ and $\mathrm{Cu}_{2} \mathrm{ZnSnSe}$, J. Appl.

$5 \quad$ Phys. 107 (2010) 053710-1-053710-8.

6 [7] M.T. Winkler, W. Wang, O. Gunawan, H.J. Hovel, T.K. Todorov, D.B. Mitzi, Optical

7 designs that improve the efficiency of $\mathrm{Cu}_{2} \mathrm{ZnSn}(\mathrm{S}, \mathrm{Se})_{4}$ solar cells, Thin Solid Films 3 (2014)

$8 \quad 1029-1036$.

9 [8] J. Kim, H. Hiroi, T.K. Todorov, O. Gunawan, M. Kuwahara, T. Gokmen, D. Nair, M.

10 Hopstaken, B. Shin, Y.S. Lee, W. Wang, H. Sugimoto, D.B. Mitzi, High Efficiency

$11 \mathrm{CuZnSn}(\mathrm{S}, \mathrm{Se})$ Solar Cells by Applying a Double InS/CdS Emitter, Adv. Mater. 44 (2014)

$12 \quad 7427-7431$.

[9] S. Schorr, H.-J. Hoebler, M. Tovar, A neutron diffraction study of the stannite-kesterite solid solution series, European Journal of Mineralogy 19 (2007) 65-73.

[10] C. Krämmer, C. Huber, C. Zimmermann, M. Lang, T. Schnabel, T. Abzieher, E.

Ahlswede, H. Kalt, M. Hetterich, Reversible order-disorder related band gap changes in $\mathrm{Cu}_{2} \mathrm{ZnSn}(\mathrm{S}, \mathrm{Se})_{4}$ via post-annealing of solar cells measured by electroreflectance, Appl. Phys. Lett. 105 (2014) 262104-1-262104-4.

[11] A.R. G. Rey, J. Sendler, T. P. Weiss, M. Thevenin, M. Guennou, B. El Adib, and S.

Siebentritt, The band gap of $\mathrm{Cu}_{2} \mathrm{ZnSnSe}_{4}$ : Effect of order-disorder, Appl. Phys. Lett. 105 (2014) 112106-1-112106-4.

[12] M. Paris, L. Choubrac, A. Lafond, C. Guillot-Deudon, S. Jobic, Solid-state NMR and Raman spectroscopy to address the local structure of defects and the tricky issue of the $\mathrm{Cu} / \mathrm{Zn}$ disorder in Cu-poor, Zn-rich CZTS materials, Inorg. Chem. 53 (2014) 8646-8653. 
1 [13] H.B. Bebb, E. Williams, Semiconductors and Semimetals, Academic Press, New York, 8 2 (1972) p. 181.

3 [14] F. Luckert, D.I. Hamilton, M.V. Yakushev, N.S. Beattie, G. Zoppi, M. Moynihan, I. 4 Forbes, A.V. Karotki, A.V. Mudryi, M. Grossberg, J. Krustok, R.W. Martin, Optical 5 properties of high quality $\mathrm{Cu}_{2} \mathrm{ZnSnSe}_{4}$ thin films, Appl. Phys. Lett. 99 (2011) 062104-1$6 \quad 062104-3$.

7 [15] M.V. Yakushev, I. Forbes, A.V. Mudryi, M. Grossberg, J. Krustok, N.S. Beattie, M. 8 Moynihan, A. Rockett, R.W. Martin, Optical spectroscopy studies of $\mathrm{Cu}_{2} \mathrm{ZnSnSe}_{4}$ thin films, $9 \quad$ Thin Solid Films 582 (2015) 154-157

10 [16] M. Grossberg, J. Krustok, K. Timmo, M. Altosaar, Radiative recombination in $11 \mathrm{Cu}_{2} \mathrm{ZnSnSe}{ }_{4}$ monograins studied by photoluminescence spectroscopy, Thin Solid Films 517 (2009) 2489-2492.

[17] S. Oueslati, G. Brammertz, M. Buffiere, C. Koble, T. Oualid, M. Meuris, J. Poortmans, Photoluminescence study and observation of unusual optical transitions in $\mathrm{Cu}_{2} \mathrm{ZnSnSe} 4 / \mathrm{CdS} / \mathrm{ZnO}$ solar cells, Sol. Energy Mater. Sol. Cells 134 (2015) 340-345.

[18] J. Márquez-Prieto, M.V. Yakushev, I. Forbes, J. Krustok, V.D. Zhivulko, P.R. Edwards, M. Dimitrievska, V. Izquerdo-Roca, N.M. Pearsall, A.V. Mudryi, and R.W. Martin, Impact of the selenisation temperature on the structure and optical properties of CZTSe absorbers, Sol. Energy Mater. Sol. Cells 152 (2016) 42-50.

[19] T. Gokmen, O. Ganawan, T.K.Todorov, and D.B. Mitzi, Band Tailing and Efficiency Limitations in Kesterita Solar Cells, Appl. Phys. Lett. 103 (2013) 103506-1-103506-5.

[20] M. Lang, T. Renz, N. Mathes, M. Neuwirth, T. Schnabel, H. Kalt and M. Hetterich, Influence of the $\mathrm{Cu}$ Content in $\mathrm{Cu}_{2} \mathrm{ZnSn}(\mathrm{S}, \mathrm{Se})_{4}$ solar cell absorbers on order-disorder related band gap changes, Appl. Phys. Lett. 109 (2016) 142103-1-142103-4. 
1 [21] J. Márquez, M. Neuschitzer, M. Dimitrievska, R. Gunder, S. Haass, M. Werner, Y.E.

2 Romanyuk, S. Schorr, N.M. Pearsall, I. Forbes, Systematic compositional changes and their

3 influence on lattice and optoelectronic properties of $\mathrm{Cu}_{2} \mathrm{ZnSnSe}_{4}$ kesterite solar cells, Sol.

$4 \quad$ Energy Mater. Sol. Cells 144 (2016) 579-585.

5 [22] M.V. Yakushev, J. Márquez-Prieto, I. Forbes, P.R. Edwards, V.D. Zhivulko, A.V.

6 Mudryi, J. Krustok, R.W. Martin, Radiative recombination in $\mathrm{Cu}_{2} \mathrm{ZnSnSe}_{4}$ thin films with $\mathrm{Cu}$

7 deficiency and Zn excess, Journal of Physics D: Appl. Phys. 48 (2015) 475109-1-475109-7.

8 [23] J. Marquez-Prieto, Y. Ren, R.W. Miles, N. Pearsall, I. Forbes, The influence of 9 precursor $\mathrm{Cu}$ content and two-stage processing conditions on the microstructure of $10 \mathrm{Cu}_{2} \mathrm{ZnSnSe}$, Thin Solid Films 582 (2015) 220-223.

[24] T. Schmidt, K. Lischka, W. Zulehner, Excitation-power dependence of the near-bandedge photoluminescence of semiconductors Phys. Rev. B 45 (1992) 8989-8994.

[25] A.P. Levanyuk, V.V. Osipov, Edge Luminescence of the Direct Gap Semiconductors, Usp. Fiz. Nauk 133 (1981) 427-477.

[26] J. Krustok, H. Collan, M. Yakushev, K. Hjelt, The role of spatial potential fluctuations in the shape of the PL bands of multinary semiconductor compounds, Physica Scr. T79 (1999) 179-182.

[27] J. Mattheis, U. Rau, J.H. Werner, Light absorption and emission in semiconductors with band gap fluctuations -A study on $\mathrm{Cu}(\mathrm{In}, \mathrm{Ga}) \mathrm{Se}_{2}$ thin films, J. Appl. Phys. 101 (2007) 113519-1-113519-11.

[28] K.P. O'Donnell, R.W. Martin, P. G. Middleton, Origin of luminescence from InGaN Diodes, Phys. Rev. Lett. 82, (1999) 237-240.

[29] M.E. White, K.P. O’Donnell, R.W. Martin, S. Pereira, C.J. Deatcher, I.M. Watson,

Photoluminescence excitation spectroscopy of InGaN epilayers, Materials Science and 
1 [30] M. Grossberg, J. Krustok, K. Timmo, M. Altosaar, Radiative recombination in

$2 \mathrm{Cu}_{2} \mathrm{ZnSnSe}_{4}$ monograins studied by photoluminescence spectroscopy, Thin Solid Films 517

3 (2009) 2489-2492.

4 [31] C. Persson, Electronic and optical properties of $\mathrm{Cu}_{2} \mathrm{ZnSnS}_{4}$ and $\mathrm{Cu}_{2} \mathrm{ZnSnSe}_{4}$, J. Appl.

5 Phys. 107 (2010) 053710-1-053710-8.

6 [32] B. Shklovskii, A. Efros, Electronic Properties of Doped Semiconductors, Springer,

7 Berlin, 1984.

8 [33] A. Jagomagi, J. Krustok, J. Raudoja, M. Grossberg, M. Danilson, M. Yakushev,

9 Photoluminescence studies of heavily doped CuInTe 2 crystals, Physica B 337 (2003) 36910374

[34] I. Dirnstorfer, M. Wagner, D.M. Hofmann, M.D. Lampert, F. Karg, B.K. Meyer,

Characterization of $\mathrm{CuIn}(\mathrm{Ga}) \mathrm{Se}_{2}$ Thin Films, physica status solidi A 168 (1998) 163-175.

[35] S. Siebentritt, N. Papathanasioua, M.Ch. Lux-Steiner, Potential fluctuations in compensated chalcopyrites Physica B 376-377 (2006) 831-833.

[36] R. Bhattacharya, B. Pal, B. Bansal, On conversion of luminescence into absorption and the van Roosbroeck-Shockley relation, Appl. Phys. Lett. 100 (2012) 222103-1-222103-4.

[37] J. Krustok, H. Collan, K. Hjelt, Does the low-temperature Arrhenius plot of the photoluminescence intensity in CdTe point towards an erroneous activation energy?, J. Appl. Phys. 81 (1997) 1442-1445.

[38] A. Lafond, L. Choubrac, C. Guillot-Deudon, P. Deniard, S. Jobic, Crystal Structures of Photovoltaic Chalcogenides, an Intricate Puzzle to Solve: the Cases of CIGSe and CZTS Materials, Materials, Z. Anorg. Allg. Chem. 638 (2012) 2571-2577.

Detection of a $\mathrm{ZnSe}$ secondary phase in coevaporated $\mathrm{Cu}_{2} \mathrm{ZnSnSe}_{4}$ thin films, Appl.Phys. 
1 [40] D. Huang, C. Persson Band gap change induced by defect complexes in $\mathrm{Cu}_{2} \mathrm{ZnSnS}_{4}$,

2 Thin Solid Films 535 (2013) 265-269.

3 [41] K. Yu and E. A. Carter, A Strategy to Stabilize Kesterite CZTS for High-Performance

4 Solar Cells, Chem. Mater. 28 (2016) $864-869$.

5 [42] C. Krämmer, C. Huber, T. Schnabel, C. Zimmermann, M. Lang, E. Ahlswede, H. Kalt,

6 M. Hettrich, Order-disorder related band gap changes in $\mathrm{Cu}_{2} \mathrm{ZnSn}(\mathrm{S}, \mathrm{Se})_{4}$ : Impact on solar

7 cell performance, Proceedings of the IEEE 42th Photovoltaic Specialist Conference (PVSC),

8 IEEE, 2015, pp. 1-4.

9 [43] J. Krustok, R. Josepson, T. Raadik and M. Danilson. Potential fluctuations in $10 \mathrm{Cu}_{2} \mathrm{ZnSnSe}_{4}$ solar cells studied by temperature dependence of quantum efficiency curves, 11 Physica B 405 (2010) 3186-3189.

12 
1 Table 1. The $[\mathrm{Cu}] /[\mathrm{Zn}+\mathrm{Sn}]$ and $[\mathrm{Zn}] /[\mathrm{Sn}]$ ratios in the films and parameters of solar cells

2 fabricated from them.

\begin{tabular}{|c|c|c|c|}
\hline Film & 1 & 2 & 3 \\
\hline$[\mathrm{Cu}] /[\mathrm{Zn}+\mathrm{Sn}]-$ & 0.86 & 0.75 & 0.66 \\
EDX & & & \\
\hline$[\mathrm{Zn}] /[\mathrm{Sn}]-\mathrm{EDX}$ & 1.00 & 1.17 & 1.24 \\
\hline$[\mathrm{Cu}] /[\mathrm{Zn}+\mathrm{Sn}]-$ & 0.99 & 0.80 & 0.72 \\
$\mathrm{XRF}$ & & & \\
\hline$[\mathrm{Zn}] /[\mathrm{Sn}]-\mathrm{XRF}$ & 1.04 & 1.18 & 1.28 \\
\hline$V_{O C}(\mathrm{mV})$ & 367 & 410 & 434 \\
\hline$J_{S C}\left(\mathrm{~mA} / \mathrm{cm}^{2}\right)$ & 33.0 & 31.9 & 31.2 \\
\hline$F F$ & 56.8 & 56.3 & 59.6 \\
\hline$\eta(\%)$ & 6.9 & 7.4 & 8.1 \\
\hline
\end{tabular}

3

4

5

6

7

8

9

10

11

12

13 
2 Table 2. Spectral energy and FWHM of the dominant PL band at $6 \mathrm{~K}$, bandgaps $E_{g}$, the 3 broadening energies $\Delta E$, average depths of potential fluctuations $\gamma$, activation energies $E_{a}$ of 4 the dominant bands temperature quenching for the films 1,2 and 3.

\begin{tabular}{|c|c|c|c|}
\hline $\begin{array}{c}\text { dominant } \\
\text { band/film }\end{array}$ & 1 & 2 & 3 \\
\hline$E_{\max }(\mathrm{eV})$ & 0.83 & 0.9 & 0.95 \\
\hline FWHM (meV) & 96 & 92 & 90 \\
\hline$j$-shift & 13 & 16 & 12 \\
$(\mathrm{meV} / \mathrm{decade})$ & 10 & & \\
\hline$k$ & 0.79 & 0.94 & 0.99 \\
\hline$E_{g}(\mathrm{eV})$ & 0.99 & 1.02 & 1.03 \\
\hline$\Delta E(\mathrm{meV})$ & 29 & 25 & 20 \\
\hline$\gamma(\mathrm{meV})$ & $39 \pm 4$ & $29 \pm 2$ & $24 \pm 1$ \\
\hline$E_{a}(\mathrm{meV})$ & $90 \pm 11$ & $98 \pm 2$ & $63 \pm 8$ \\
\hline
\end{tabular}

5

6

7

8

9

10

11 
1 Fig.1. Normalised PL spectra of the films measured at $6 \mathrm{~K}$ using similar optical alignments

2 and laser excitation on a linear intensity scale.

3

4 Fig.2. Excitation intensity dependencies of the PL spectra in film 1 (a), film 2 (b) and film 3

5 (c) measured at $6 \mathrm{~K}$, the dependence of the integrated PL intensity $I$ of the observed bands on

6 the excitation laser power $P(\mathrm{~d})$.

7

8 Fig.3. Temperature dependent PL spectra from film 1 (a), film 2 (b) and film 3 (c).

Fig.4. PLE spectra (measured at the energy corresponding to the maxima of the dominant PL bands) of film 1 (a), film 2 (b) and film 3 (c) with PL spectra measured at $4.2 \mathrm{~K}$. Red solid lines in the PLE spectra show the fitting results.

Fig.5. The PL spectra (shown by symbols) of film 1 (a), 2 (b) and 3 (c), taken at $6 \mathrm{~K}$, fitted by asymmetric double sigmoidal functions (shown by red solid lines). The bands at $0.83 \mathrm{eV}$ and $0.93 \mathrm{eV}$ in the PL spectrum of film 1 (a) are fitted by the blue and magenta dashed lines, respectively.

Fig.6. The temperature dependence of $W_{l}$ of the dominant bands in the PL spectra of film 1 (घ), film $2(\bullet)$ and film $3(\bullet)$ (a). The temperature dependence of $E_{\max }$ of the bands in the PL spectra of film 1 (for the bands at $0.83 \mathrm{eV}-\square$ and $0.93 \mathrm{eV}-\mathbf{-})$ ), film $2(\circ)$ and film $3(\diamond)$ (b).

Fig.7. Arrhenius plots of the integrated intensities of the bands in the PL spectra of film 1(a), 2 (b) and 3(c). 
$1 \quad$ Fig.1

2

3

4

5

6

7

8

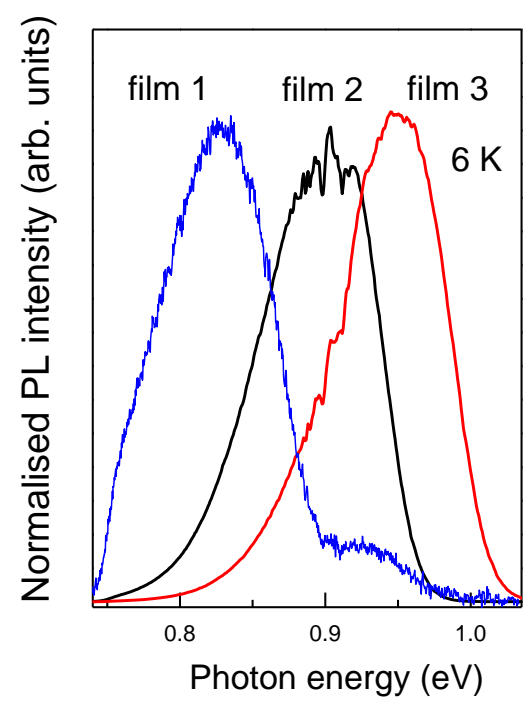

9

10

11

12

13

14

15

16

17

18 
$1 \quad$ Fig.2

2

3

4

5

6

7

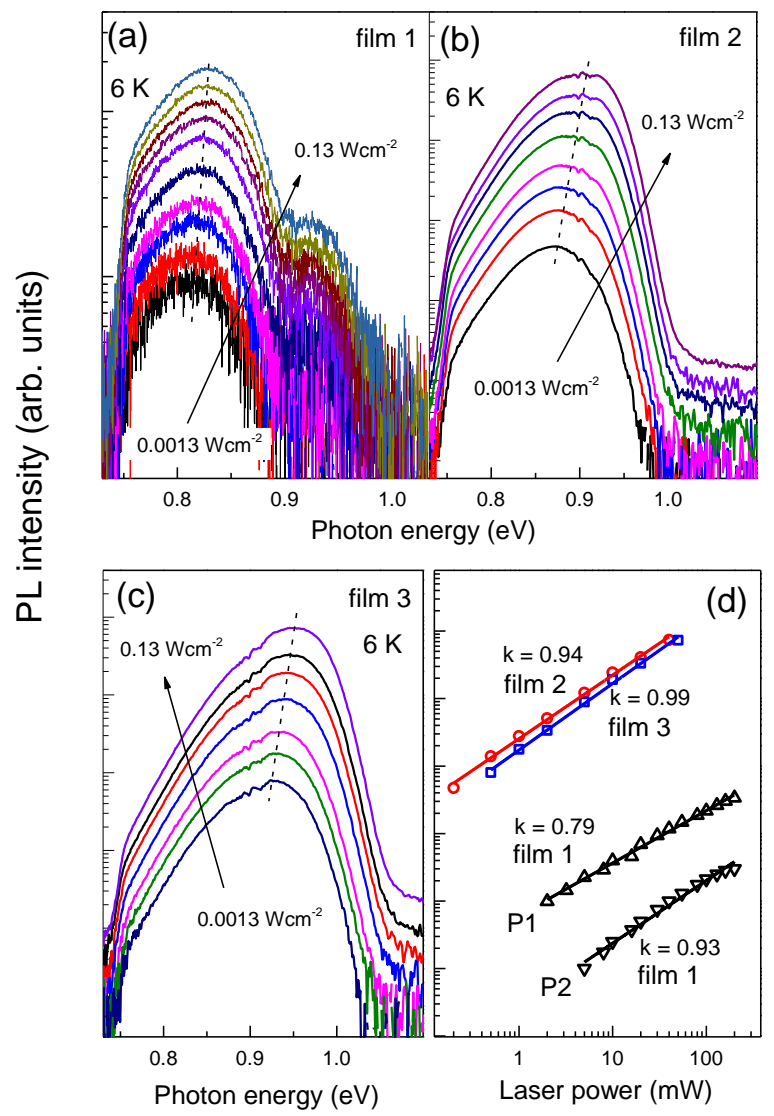

8 


\section{Fig. 3}

2

3

4

5

6

7

8



9

10

11

12

13

14

15

16

17

18

19 
$1 \quad$ Fig.4

2

3

4

5

6

7

8

9



10

11

12

13

14

15

16

17

18

19

20 
$1 \quad$ Fig.5

2

3

4

5

6

7

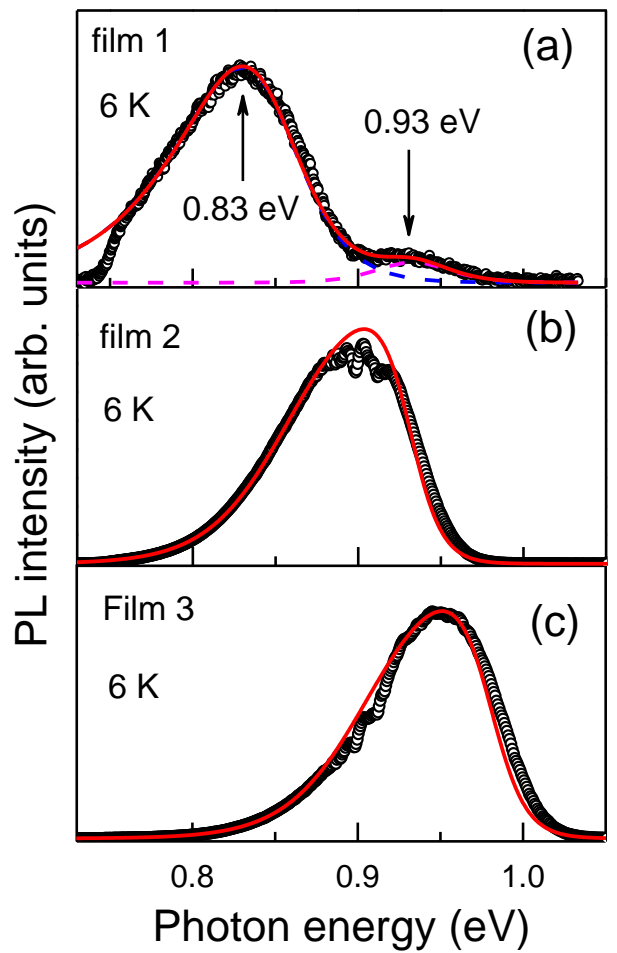

8

9

10

11 
$1 \quad$ Fig.6

2

3

4

5

6

7

8

9

10

11

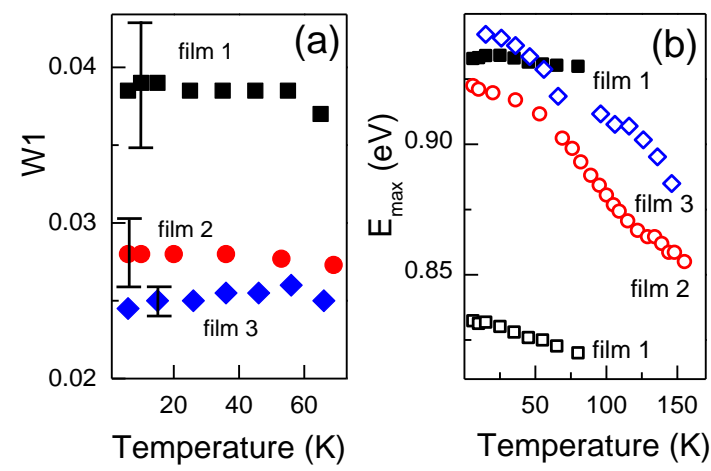

13 
$1 \quad$ Fig.7

2

3

4

5

6

7

8

9

10

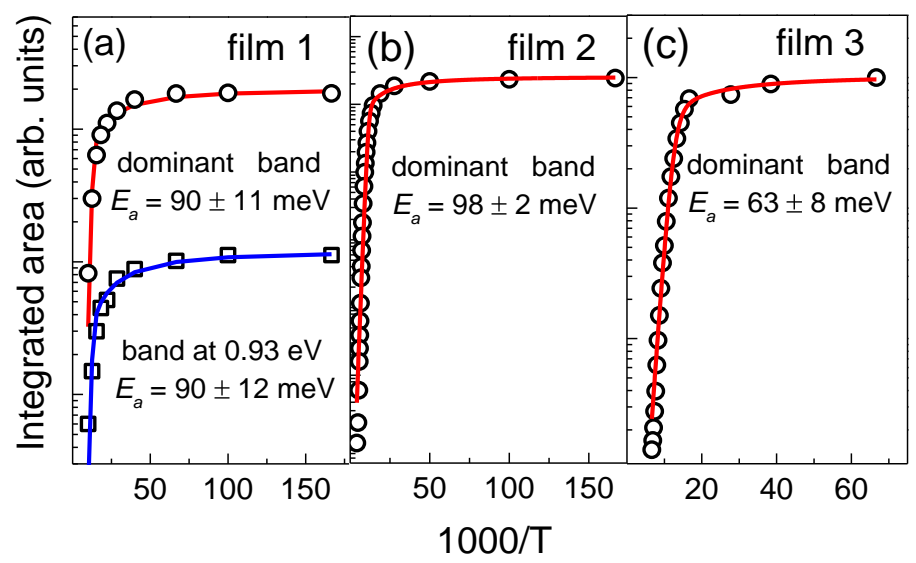

11

12

13

14 